\title{
Endotracheal Suctioning: Effectiveness of Structured Training Program in Enhancing Performance Knowledge of Intensive Care Unit Nurses
}

\author{
Kanwal Qaiser RN, RM, Post RN BSN, MSN ${ }^{1 *}$, Yasmeen Saggu RN, RM, DTA, DWA, MSN², Sabrina Javed RN, RM, \\ Post RN BSN, MSN ${ }^{3}$, Dr Mansoor Ghani MBBS, MPHIL, MHPE ${ }^{4}$, Sumaira Naz Generic BSN, MPH ${ }^{5}$, Meshal Margrate \\ Generic BSN, MSN ${ }^{6}$
}

${ }^{1}$ Senior Nursing Lecturer, Institute of Nursing, Wah Medical College, Wah Cantt

${ }^{2}$ Principal, Fauji Foundation College of Nursing, Rawalpindi

${ }^{3}$ Senior Nursing Lecturer, Institute of Nursing, Wah Medical College, Wah Cantt

${ }^{4}$ Associate Professor, Biochemistry, University of Health Sciences, Lahore

${ }^{5}$ Generic BSN, MPH. Assistant Professor, Institute of Nursing, Wah Medical College, Wah Cantt

${ }^{6}$ Principal, College of Nursing, Akhter Saeed Medical and Dental College, Lahore

DOI: $10.36348 /$ sjnhc.2020.v03i01.003 $\quad$ | Received: 11.12 .2019 | Accepted: 18.12 .2019 | Published: 24.01 .2020

*Corresponding author: Kanwal Qaiser

Email: kanwal.qaiser.gill@gmail.com

\section{Abstract}

Mechanical ventilation is a lifesaving modality in critically ill patients. It is achieved through passage of Endotracheal Tube in the trachea for the assistance in breathing and removal of tracheal secretions. ETT tends to interfere in the function of mucociliary ladder putting the patient at risk for accumulation of secretions which requires an utmost need for endotracheal suctioning. This invasive procedure ensures the patency of ETT and deliverance of adequate oxygenation to the patient, but lack of knowledge and malpractices of the nurses tends to put the patient at risk for certain complications. The study was aimed to evaluate the effectiveness of structured training program in enhancing performance knowledge of ICU nurses in terms of ETT suctioning. For the evaluation of knowledge and skill, a questionnaire and observational checklist was developed along with the protocol of ETT suctioning in the context of evidence based guidelines. Quasi experimental design was chosen with purposive sampling technique. The sample size was 50 students of Post Basic Diploma in ICU/CCU from various college of nursing of Lahore and Islamabad. Findings of the study proposed that post implementation knowledge and practices of ICU nurses were immensely improved with p value of 0.00 , respectively. Henceforth, the structured training program proved to be promising and had a meaningful influence to enhance the performance knowledge of ICU nurses in relation to ETT suctioning guidelines.

Keywords: Endotracheal Tube (ETT), Mechanical ventilation, ICU nurses.

Copyright @ 2020: This is an open-access article distributed under the terms of the Creative Commons Attribution license which permits unrestricted use, distribution, and reproduction in any medium for non-commercial use (NonCommercial, or CC-BY-NC) provided the original author and source are credited.

\section{INTRODUCTION}

Mechanical ventilation is a lifesaving modality for critically ill patients. It is achieved through passing Endotracheal Tube (ETT) in the trachea for the assistance in breathing and removal of tracheal secretions. Patients on mechanical ventilator are critically ill and they are in intense need for endotracheal suctioning therapy for proper oxygenation. It is the obligation of nurse to provide holistic care to mechanically ventilated patients and put off the technical hitches related to suctioning procedure. It necessitates an utmost requirement of robust evidence based knowledge on the part of a nurse [1].

The patients on mechanical ventilators require frequent suctioning because of interference of endotracheal tube in the mucociliary function of respiratory tract cells leading to accumulation of secretions [2]. Endotracheal suctioning is one of the critical nursing care interventions performed in order to remove accumulated tracheal secretions from the patient's respiratory tract and to maintain its patency. The procedure requires competent skills on the part of health professionals to prevent the complications and hazards [3].

The ETT suctioning intervention accompanies many of the complications that prolong patient's stay in hospital and further deteriorates his condition [4]. Mechanical ventilation and tracheal suctioning puts the patient at risk for catching nosocomial infections and ventilator associated complications. 
VAP is commonest nosocomial infection in intubated patients with 6 to 20 times higher prevalence rates for at least 48 hours after intubation [5]. It contributes to $30 \%$ mortality rate in ventilated patients [6]. A number of other complications are associated with malpractice of ETT suctioning such as lesions in the tracheal mucosa, pain, discomfort, infection, variations in the hemodynamic parameters and arterial gases measurements, bronchoconstriction, atelectasis, raised intra-cranial pressure, and alterations in cerebral blood flow. Hypoxia is one of the most common complications which is avertible as well [7].

The foremost principles to prevent VAP and other complications are education of the staff, reduction in colonization of ETT and respiratory tract through infection control measures and avoidance of aspiration of subglottic secretions into lower respiratory tract. Educating the staff holds the highest value for the prevention of VAP and other complications. The study also stressed that such education sessions should be continued with respect to time to keep the staff familiarized about the current evidence based practices. This eventually will help in the early weaning of patients from mechanical ventilator and will also reduce the burden of complications [8].

Educating the nurses in terms of evidence based guidelines has proved to be promising in the reduction of complications associated with the procedure. It is evident by dramatic reduction in the incidence of Ventilator Associated Pneumonia by $38 \%$ after educational intervention carried out in paediatric ICU [9].

Zeb A et al., [1] also conducted a study at tertiary care hospitals of Peshawar, Pakistan. The results witnessed that knowledge and practice level of ICU nurses in terms ETT suctioning was satisfactory but chances exist for further enrichments. Policies and Procedures should be hosted in the light of evidence based guidelines to dispense competent care with fewer complications.

One more study indicated that nurses were short of correct knowledge and skills relevant to endotracheal suctioning and it tend to supplemented complications such as mucosal injuries, pain, discomfort, infection, changes in heart rate and blood pressure ,bronchoconstriction, atelectasis, increase in intra-cranial pressure, and modification in cerebral blood flow [10]. Hence, the patient's outcome can be improved if the guidelines are followed appropriately by health professionals [5].

Another investigation carried out in 2010 proclaimed that the practices of airway management on mechanical ventilated patients were not being executed in the light of standard guidelines. It was concluded that consistent management of mechanically ventilated patients was crucial in the prevention of complications which could be improved by continued education and surveying the ICU nurses from time to time [11].

A study by Jansson $\mathrm{M}$ et al., [12] revealed that nurses were not following the current guidelines of endotracheal suctioning. There was a huge dissimilarity between their knowledge and practices. The most considerable inconsistencies were found in following the infection control measures during endotracheal suctioning. Educational interventions and clinical guidelines were suggested to reduce the infection rates.

Salvatore M M et al., [13], also conducted a study in which health professionals were enrolled in continued education program and were informed about the current guidelines of performing tracheal suctioning, the toll of complications was reduced dramatically from $12.4 \%$ to $4.9 \%$. This proves to be the notable realization of nursing education sessions.

Leddy $\mathrm{R}$ [14] too identified in a study that endotracheal suctioning was not being carried out under the light of evidence based guidelines by nurses in ICU. The survey also testified that a remarkable number of respondents were unacquainted of the present suctioning protocol. This highlighted the immense need to educate nurses to decrease the detrimental effects of this procedure such as reduced oxygen saturation, patient distress and VAP.

The obligation of the nurse is to provide holistic care to mechanically ventilated patients and put off the technical hitches related to suctioning procedure. It necessitates an utmost requirement of robust evidence based knowledge on the part of a nurse [1]. However if nurses follow the standard guidelines while suctioning, the risks of developing complications due to mechanical ventilation decreases [13].

While reviewing the literature it was concluded that consistent management of mechanically ventilated patients was crucial in the prevention of complications which could be improved by continued education and surveying the ICU nurses from time to time. Therefore, it stimulated the researcher to evaluate the effectiveness of endotracheal suctioning training in the light of evidence based guidelines to enhance knowledge and practices of ICU nurses.

\section{MATERIALS AND METHODS}

The study was implemented at four different college of Nursing at Lahore and Islamabad with nurses doing post basic diploma in ICU/CCU specialty.

The endotracheal suctioning protocol is organized and methodical written strategies about endotracheal suctioning which comprises of objectives and indications of endotracheal suctioning, essential equipments and stages of carrying out endotracheal 
suctioning, nursing care and special attentions during endotracheal suctioning which was established and authenticated by specialists in the arena of nursing and medical science. Practicability of employing protocol was tested through pilot study.

Data was collected by the means of sample characteristics proforma, structured knowledge questionnaire having 22 knowledge items regarding endotracheal suctioning with maximum possible score of 22 and observation checklist involving 38 items regarding endotracheal suctioning with maximum possible score of 38. The tools in the study were established after extensive review of literature, expert's direction and validated by experts in the field of Medical-Surgical Nursing. Reliability of structured knowledge questionnaire was found to be 0.647 . Total sample of 50 nursing students of post basic specialty of ICU/CCU nurses working in intensive care units for more than a year and executing direct patient care were selected by purposive sampling technique.

The study proposal was approved by synopsis review committee and ethical review committee of University of Health Sciences, Lahore.

Data was collected from all four College of Nursing from Lahore and Islamabad via structured questionnaire ad checklist. Training regarding ETT suctioning was delivered on the manikin after the video session. All collected information was entered in computer and analysis was done through Statistical Package for the Social Sciences (SPSS) version 20.0. Data was analyzed by using both descriptive and inferential statistics.

\section{RESULTS}

Table-1

\begin{tabular}{|l|l|l|}
\hline Sample characteristics & Frequency \\
\hline \multirow{2}{*}{ Age } & $21-28$ years & 32 \\
\cline { 2 - 3 } & $29-36$ years & 13 \\
\cline { 2 - 3 } & $>36$ years & 5 \\
\hline \multirow{2}{*}{ Gender Distribution } & Females & 30 \\
\cline { 2 - 3 } & Males & 20 \\
\hline Professional Education & Diploma in Nursing & 49 \\
\cline { 2 - 3 } & Generic BSN & 01 \\
\hline Professional Experience & $1-5$ years & 42 \\
\cline { 2 - 3 } & $6-10$ years & 7 \\
\cline { 2 - 3 } & $11-15$ years & 1 \\
\hline Frequency of Participants According to different College of Nursing. & CON PIMS & 19 \\
\cline { 2 - 3 } & CON Shifa & 13 \\
\cline { 2 - 3 } & CON National Hosp & 07 \\
\cline { 2 - 3 } & PGCN & 11 \\
\cline { 2 - 2 } & Yes & 17 \\
\hline \multirow{2}{*}{ Any in-service education related to endotracheal suctioning } & No & 33 \\
\hline
\end{tabular}

According to Table-1 majority of post basic diploma ICU/CCU nurses $(60 \%)$ were female whereas more personnel (64\%) were found between 21-28 years age group. Almost all of the participants had Diploma in Nursing i.e. $98 \%$. $84 \%$ of the post basic diploma were having experience between 1 to 5 years, while only $14 \%$ of them had experience more than 5 years. Less than half of the participants had attended workshop on ETT suctioning protocol.
Evaluation of the effectiveness of endotracheal suctioning protocol regarding knowledge of ICU nurses

Table-2 is clearly depicting the enhancement of nurses' knowledge about ETT suctioning after training session. Paired sample statistic is also supporting the data with significant $p$ value i.e. $<0.05$. Thus, the training session proved to be promising in attaining the objectives of study.

Table-2: Knowledge of ICU nurses regarding ETT suctioning before \& after training session

\begin{tabular}{|l|l|l|l|l|}
\hline Knowledge Categories & $\begin{array}{l}\text { Frequency } \\
\text { (pre-training) }\end{array}$ & $\begin{array}{l}\text { Percentage } \\
\text { (pre-training) }\end{array}$ & $\begin{array}{l}\text { Frequency } \\
\text { (post-training) }\end{array}$ & $\begin{array}{l}\text { Percentage } \\
\text { (post-training) }\end{array}$ \\
\hline Poor Knowledge $(<50 \%)$ & 28 & 56.0 & 0 & 0 \\
\hline Average Knowledge $(50-69 \%)$ & 20 & 40.0 & 13 & 26.0 \\
\hline Adequate Knowledge $(70-79 \%)$ & 2 & 4.0 & $\mathbf{1 6}$ & $\mathbf{3 2 . 0}$ \\
\hline Good Knowledge (80\% \& Above) & 0 & 0 & $\mathbf{2 1}$ & $\mathbf{4 2 . 0}$ \\
\hline Total & $\mathbf{5 0}$ & $\mathbf{1 0 0 . 0}$ & $\mathbf{5 0}$ & $\mathbf{1 0 0 . 0}$ \\
\hline
\end{tabular}


Paired Sample Statistics

\begin{tabular}{|c|c|c|l|l|}
\hline & Mean & $\mathbf{N}$ & Std. Deviation & Std. Error Mean \\
\hline Pre-knowledge & 1.4800 & 50 & .57994 & .08202 \\
Post-knowledge & 3.1600 & 50 & .81716 & .11556 \\
\hline
\end{tabular}

Paired Sample Statistics

\begin{tabular}{|c|c|c|c|c|c|c|c|c|}
\hline \multirow{5}{*}{$\begin{array}{l}\text { Pre-knowledge - } \\
\text { Post-knowledge }\end{array}$} & \multirow{2}{*}{\multicolumn{5}{|c|}{ Paired Differences }} & \multirow{4}{*}{$\mathrm{t}$} & \multirow{4}{*}{ Df } & \multirow{4}{*}{$\begin{array}{l}\text { Sig. (2- } \\
\text { tailed) }\end{array}$} \\
\hline & & & & & & & & \\
\hline & \multirow[t]{2}{*}{ Mean } & \multirow[t]{2}{*}{$\begin{array}{l}\text { Std. } \\
\text { Dev }\end{array}$} & \multirow{2}{*}{$\begin{array}{l}\text { Std. } \\
\text { Error } \\
\text { Mean }\end{array}$} & \multicolumn{2}{|c|}{$\begin{array}{l}95 \% \text { Confidence Interval } \\
\text { of the Difference }\end{array}$} & & & \\
\hline & & & & Lower & Upper & & & \\
\hline & 1.68000 & 1.03884 & .14691 & 1.97523 & 1.38477 & 11.435 & 49 & .000 \\
\hline
\end{tabular}

Practices of ICU nurses in terms of practices before and after training session among ICU nurses

Table- 3 is portraying the notable improvement in practices of ICU nurses before and after training session. The prominent difference between both the scores is also being supported by the p value of 0.00 in test statistic given below. Thus, the training session proved to be impactful in attaining the objectives of the study.

Table-3: Practices of ICU nurses about ETT suctioning against observational checklist before and after delivering training program

\begin{tabular}{|l|l|l|l|}
\hline \multicolumn{2}{|c|}{ PRE CHECKLIST SCORE } & POST CHECK LIST SCORE \\
\hline Inadequate & Adequate & Inadequate & Adequate \\
\hline 44 & $\mathbf{0 6}$ & 09 & $\mathbf{4 1}$ \\
\hline Total: 50 & Total: 50 & \\
\hline
\end{tabular}

Test Statistic

\begin{tabular}{|l|l|}
\hline \multicolumn{2}{|l|}{ Total pre checklist score \& Total post check list score } \\
\hline $\mathrm{N}$ & 50 \\
\hline Chi-Square & 33.029 \\
\hline Asymp. Sig. & $\mathbf{. 0 0 0}$ \\
\hline
\end{tabular}

Table-4 symbolizes the success of training session by analogizing pre-and post-knowledge score and pre and post practice score with reference to ETT suctioning procedure after training session. Wilcoxon Signed Rank test was employed which unveiled that the training session was exceedingly conducive and demonstrated to inculcate the evidence based knowledge and practices about ETT suctioning among ICU nurses with $\mathrm{p}$ value $<0.001$.

Table-4: Post-knowledge and practices of ICU nurses in terms of endotracheal suctioning after training session by Wilcoxon Signed Rank Test

\begin{tabular}{|c|c|c|c|c|c|}
\hline \multicolumn{2}{|c|}{ Wilcoxon Signed Ranks Test } & \multirow{2}{*}{$\begin{array}{l}\mathbf{N} \\
0^{\mathrm{a}}\end{array}$} & \multirow{2}{*}{$\begin{array}{l}\text { Mean } \\
\text { Rank } \\
.00\end{array}$} & \multirow{2}{*}{$\begin{array}{l}\text { Sum of } \\
\text { Ranks } \\
.00\end{array}$} & \multirow{2}{*}{$\begin{array}{l}\text { Test Statistics } \\
\text { Z } 5.544\end{array}$} \\
\hline \multirow{3}{*}{$\begin{array}{l}\text { Post knowledge - CHECK } \\
\text { LIST SCORE }\end{array}$} & Negative Ranks & & & & \\
\hline & Positive Ranks & $38^{\mathrm{b}}$ & \multirow{3}{*}{19.50} & \multirow{3}{*}{741.00} & \multirow{3}{*}{$\begin{array}{l}\text { Asymp. Sig. (2-tailed) } \\
0.000\end{array}$} \\
\hline & Ties & $12^{\mathrm{c}}$ & & & \\
\hline \multicolumn{2}{|l|}{ Total } & 50 & & & \\
\hline
\end{tabular}

\section{DISCUSSION}

Several patients in ICUs are on mechanical ventilators due to their critical illness. Endotracheal tube (ETT) is a mode to connect patients to mechanical ventilators for proper oxygenation. But the tube can cause poor cough reflex and interfere in the function of mucociliary escalator which results in production of copious amount of secretions.

To maintain the patency of ETT, removal of secretions and dispense proper oxygenation, Endotracheal Suctioning (ETS) becomes necessary practice in ICUs which is frequently performed by nurses. At the same time, the intervention also possess certain potential hazards which can further deteriorate the patient's condition. The complications include hypoxemia, pain, nosocomial infections tracheal lesions, increased intracranial pressure, bronchoconstriction and atelectasis. Ventilator Associated Pneumonia (VAP) is notorious among all problems caused by malpractices of ETS. Therefore, it is mandatory for nurses to be aware of the current evidence based guidelines related to the procedure [7].

Continued Nursing Education is the key concept that instills nurses with contemporary 
knowledge and practices. It allows the nurses to become aware of evidence based guidelines in caring for patients to provide cost effective care for hastened recovery with negligible complications [15].

The current study embraced an Experimental with Quasi-Experimental research method on fifty nursing personnel working in intensive care units more than a year and studying post basic diploma in ICU/ CCU at various college of Nursing. The outcomes of the present study nominated that the mean postimplementation knowledge score and practice scores in areas of knowledge questionnaire and observation checklist has raised expressively as compared to the mean pre-implementation knowledge score and practice score as apparent from ' $t$ ' test $(<0.05)$.

The findings are found to be compatible with a Spanish study proposed by Gatell J R et al., [16]. 95 nurses were selected and given training session to enhance the knowledge and practices about ETT suctioning. Another study by Jannson M et al., [17], is found to be consistent in terms of results with the present study. The study showcased prominent results while determining the pre and post knowledge of ICU nurses before and after training program.

Relatively parallel results were learnt in study administered at Aga Khan University Hospital, Pakistan. The study comprised of single group of 40 nurses with pre-test and post-test design. A dramatic rise in nurses' knowledge after a teaching module was witnessed and the educational activity proved to be effective and highly appreciated [5].

The present study proved to be consistent with another study performed by Wallis, Laura [18], notifying that nurses working in ICUs more than a year did not have the adequate knowledge and skills. The reasons could be lack of knowledge, lack of support, attitude of nurse managers in the application of evidence based guidelines, lack of mentorship and lack of continuing nursing education programs in hospitals.

The findings of this study are proved to be congruent with many other prior education based methods. The education session conducted in India also exhibited the efficiency of structured training program to heighten performance knowledge among ICU nurses [2].

Another cross sectional descriptive study conducted at Peshawar, Pakistan has revealed that nurses of medical and surgical ICU in tertiary care hospitals possessed average knowledge and skills about ETT suctioning but there was a considerable room for improvement [1].

An Iranian study by Heidari M, Shahbazi S [19], also proposed that all nurses of Vali- Asr hospital owned the average knowledge with reference to airway suctioning techniques, but for the retention of knowledge and consumption of evidence based guidelines by nurses for patient care, in service teaching modules and workshops were suggested.

In contrast, another Iranian study was conducted to find the gaps between knowledge and performance of nurses in the context of endotracheal suctioning among ICU nurses. The findings of current study are much corresponding to above mentioned study. The study proclaimed that even though the nurses have had pertinent knowledge but their skills required abundant amelioration [20].

The present study concluded that that nurses acquired the full advantage of training session and their post training knowledge and skills improved substantially. Consequently, the burden of complications on patients will be reduced with the implementation of evidence based guidelines and the care provided will be cost effective.

The study is implying that knowledge and performance of ICU nurses regarding ETT suctioning can be enriched by attending training sessions which can inculcate research findings in their daily work routine. Financial burden on hospitals will also be minimized by dispensing quality and cost effective care.

There is intense need to do further research to identify barriers that hinder nurses to apprise knowledge and skills. Respiratory care written policies and procedures should be developed and employed in ICUs to uphold evidence based practices. Implementation of learnt theory and evidence based guidelines while performing ETT suctioning should be supervised in clinical settings to appraise its impression on quantifiable outcomes. Supplementary testing with bigger and diverse sample size is obligatory to step up the generalizability of the study conclusions.

Furthermore, it is highly endorsed to the Policy Makers, Stake Holders and Infection Control Committee of Health Care Management System to incorporate current evidence based guidelines regarding the procedure and integrate them to the Standard Operating Procedures in intensive care units and other units of the hospitals as well.

\section{REFERENCES}

1. Zeb, A., Ali, F., Hussain, N., Shah, S. H. A., \& Faisal, S. (2017). Knowledge and practice of ICU nurses regarding endotracheal suctioning in tertiary care hospitals, Peshawar. JOJ Nurse Health Care, 2(4), 555-595.

2. Sharma, S., Sarin, J., \& Kaur Bala, G. (2014). Effectiveness of endotracheal suctioning protocol, In terms of knowledge and practices of nursing 
personnel. Nursing and Midwifery Research Journal, 10(2), 47-60.

3. Khimani, R., Rattani, S., \& Awan, M. S. (2015). Practices of tracheal suctioning technique among health care professionals: literature review. International Journal of Nursing Education, 7(1), 179.

4. Gillies D., \& Spence, K. (2013). Deep versus shallow suction of endotracheal tubes in ventilated neonates and young infants (Review). The Cochrane Library, 6:1-12.

5. Meherali, S. M., Parpio, Y., Ali, T. S., \& Javed, F. (2011). Nurses' knowledge of evidence-based guidelines for prevention of ventilator-associated pneumonia in critical care areas: a pre and post test design. Journal of Ayub Medical College, 23(1), 146-149.

6. Theron, W. F. D. (2002). The dynamics of an elastic hopping hoop. Mathematical and computer modelling, 35(9-10), 1135-1147.

7. Nishamol, Y. N. (2011). A study to assess the knowledge and practice of endotracheal suctioning among neuro nurses SCTIMST. Research project for diploma in Neuro Nursing, Sree Chitra Tirunal Institute for Medical Sciences and Technology, Trivandrum; 1-14.

8. Hooser, V. T. (2014). Ventilator associated pneumonia (VAP), Best practice strategies for care givers. American Journal of Nursing; 5:1-10.

9. Babcock, H. M., Zack, J. E., Garrison, T., Trovillion, E., Jones, M., Fraser, V. J., \& Kollef, M. H. (2004). An educational intervention to reduce ventilator-associated pneumonia in an integrated health system: a comparison of effects. Chest, 125(6), 2224-2231.

10. Favretto, D. O., Silveira, R. C. D. C. P., Canini, S. R. M. D. S., Garbin, L. M., Martins, F. T. M., \& Dalri, M. C. B. (2012). Endotracheal suction in intubated critically ill adult patients undergoing mechanical ventilation: a systematic review. Revista latino-americana de enfermagem, 20(5), 997-1007.

11. Kjonegaard, R., Fields, W., \& King, M. L. (2010). Current practice in airway management: a descriptive evaluation. American Journal of Critical Care, 19(2), 168-173.
12. Jansson, M. (2013). The effectiveness of education on critical care nurses' knowledge and skills in adhering to guidelines to prevent ventilatorassociated pneumonia, Journal of D Medica, 1237(4):952-978.

13. Maggiore, S. M., Lellouche, F., Pignataro, C., Girou, E., Maitre, B., Richard, J. C. M., ... \& Brochard, L. (2013). Decreasing the adverse effects of endotracheal suctioning during mechanical ventilation by changing practice. Respiratory care, 58(10), 1588-1597.

14. Leddy, R., \& Wilkinson, J. M. (2015). Endotracheal suctioning practices of nurses and respiratory therapists: how well do they align with clinical practice guidelines?. Canadian journal of respiratory therapy: $C J R T=$ Revue canadienne de la therapie respiratoire: $R C T R, 51(3), 60$.

15. Eslamian, J., Moeini, M., \& Soleimani, M. (2015). Challenges in nursing continuing education: A qualitative study. Iranian journal of nursing and midwifery research, 20(3), 378-386.

16. Jam Gatell, M. R., Santé Roig, M., Hernandez Vian, O., Carrillo Santin, E., Turegano Duaso, C., Fernandez Moreno, I., \& Valles Daunis, J. (2012). Assessment of a training programme for the prevention of ventilator-associated pneumonia. Nursing in critical care, 17(6), 285292.

17. Jansson, M., Ala-Kokko, T., Ylipalosaari, P., \& Kyngäs, H. (2013). Evaluation of endotrachealsuctioning practices of critical-care nurses-An observational correlation study. Journal of Nursing Education and Practice, 3(7), 99.

18. Wallis, L. (2012). Barriers to implementing evidence-based practice remain high for US nurses. AJN The American Journal of Nursing, 112(12), 15.

19. Heidari, M., \& Shahbazi, S. (2017). Nurses' awareness about principles of airway suctioning. Journal of clinical and diagnostic research: JCDR, 11(8), LC17-LC19.

20. Ansari, A., Masoudi Alavi, N., Adib-Hajbagheri, M., \& Afazel, M. (2012). The gap between knowledge and practice in standard endo-tracheal suctioning of ICU nurses, Shahid Beheshti Hospital. Iran J Crit Care Nurs, 5(2), 71-6. 